\title{
The Measuring Engagement $\left(\mathrm{ME}^{\mathrm{TM}}\right)$ Tool
}

\author{
Normahdiah S. Said, \\ Faculty of Modern Languages and Communication, \\ Universiti Putra Malaysia (UPM) \\ Malaysia \\ normahdiah@upm.edu.my \\ norma@,fbmk.upm.edu.my \\ madiah69@yahoo.com
}

\author{
Nadiah Suboh \\ Faculty of Modern Languages and Communication, \\ Universiti Putra Malaysia (UPM) \\ Malaysia \\ nadiahsuboh@yahoo.com
}

Received: April 20, 2019. Revised: June 16, 2021. Accepted: October 18, 2021. Published: November 24, 2021.

\begin{abstract}
Studies on human engagement behavior whilst interacting with multimedia environment has now become very important due to the era of convergences of immersive technology in various digital platforms. This paper will describe a system to measure human engagement behavior in NORMA (Natural Observation and Reflection of Multimedia Application) experimental setting. The tool was developed as a Proof of Concept of The NEMD MODEL (Norma ${ }^{\mathrm{TM}}$ Engagement Multimedia Design Model) a renamed of An Engaging Multimedia Design Model that could explain the engagement phenomenon that has enticed the use of virtual spaces to complement its physical form. This paper is a description of The Measuring Engagement $\left(\mathrm{ME}^{\mathrm{TM}}\right)$ Tool automated system in comparison to a system done manually. The system has proven to be a useful tool to enable us knows more about engagement and the phenomenon surrounding it. Findings could help us know more about engagement that may lead to excessive, immersive and addictive use of innovative technologies.
\end{abstract} tool

Keywords—-multimedia; model; engagement; engaging; system;

\section{INTRODUCTION}

This invention is an automated system to measure human engagement behavior when interacting with a multimedia interface. The invention named The Measuring Engagement (METM) tool is a NEMD version 2.0 system developed from a theoretical model The NEMD MODEL (Norma $^{\mathrm{TM}}$ Engagement Multimedia Design) Model [1, 2, 3]. This version is fully automated version which includes a d atabase that collects exact facial expressions and interface in-real time during interaction. The data stored in the database will give a record of all events which include facial expression, interface and engagement levels at the time it occurs.

\section{ENGAGEMENT}

Engagement a psychological phenomenon is logically something that could not be measured but is an important psychological phenomenon that could determine the success or a failure of a design system.

Special thanks to sponsors:

Universiti Putra Malaysia (UPM) and Ministry of Education, Higher

Education Division, Government of Malaysia
According to research findings to prove the model, a system, be it a multimedia or a website application, is termed "successful" if the system could engage and sustained engagement. Engagement here can be defined as "Any form of representation of systems' design that could make the user or audience 'remain seated', 'be fully engrossed', which is referred to as "fully engaged' and has "the ability to sustain the engagement level, at a reasonable period of time of one to two hours or more" is a vital factor to "ensure user engagement" and will be defined as "successful" by the enduser or audience" [4]. Since most systems are gauge based on successfulness a system is a failure if it fails to engage the user. Therefore engagement is an important phenomenon in the evaluation of the design and development of multimedia application in various digital platforms.

\section{BACKGROUND DEVELOPMENT OF TOOL}

A form of system must be created to measure engagement. A manual system developed in 2004 is now named as NEMD version 1.0 (patent filled in 2009) was the first attempt in creating a system to measure engagement. The system was developed to assists the researcher in determining factors that cause users to be more engaged in one multimedia application to that of the other. The system was created and used in an experimental study towards the development of An Engaging Multimedia Design Model renamed The NEMD MODEL (Norma $^{\mathrm{TM}}$ Engagement Multimedia Design) Model after an extended research to prove it $[1,2,3]$.

A statistical data that has successfully been gathered by using this measuring system has proven that a tool could be created to measure engagement. The tool which was then a manual system has managed to measure engagement in various experimental conditions when the children were playing an engaging edutainment game The Sims - The People Simulator from the Creator of SimCity [CD-ROM] US, Electronic Arts (Maxis) (2000) to develop the engagement model. The data gathered from using the tool has helped the research knows more about engagement and the phenomena surrounding it. Some statistical data samples as seen in Fig 1, Fig. 2 and Fig. 3 below has given the researcher a basis to discover more about engagement and how engagement has 
enticed the use of virtual spaces to complement its physical form. .

a. Statistical Results of Study 3 - Testing the Engaging Multimedia Design Model using Kruskal-Wallis Tests)
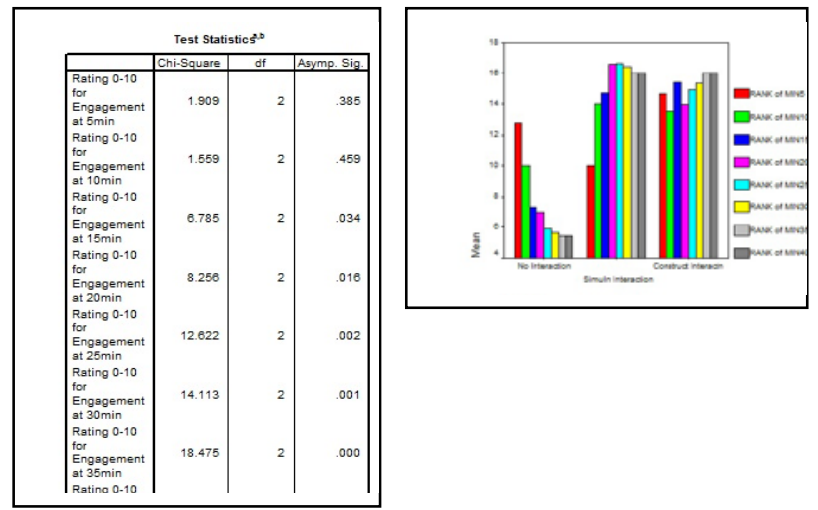

Fig.1: Statistical Analysis of Experimental Data Study 3- Testing the Model [6]

b. Statistical Results of Study 4 - A Study of Previous Experience SIMS WE Group (With Experience) versus SIMS WOE (Without Experience) Group

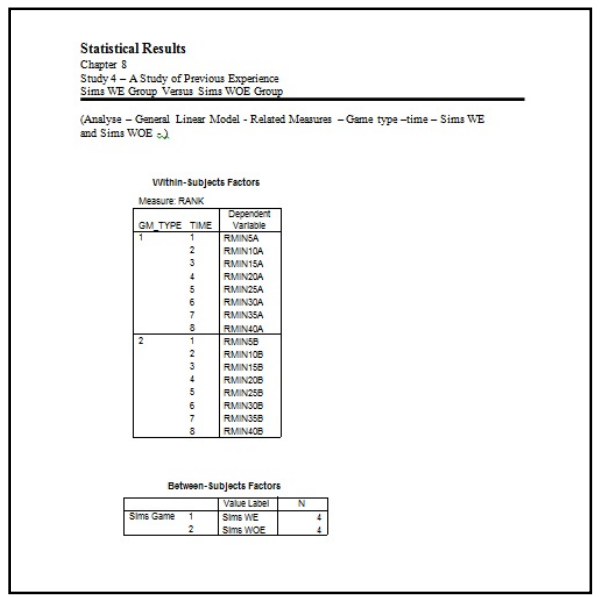

Fig.2: Statistical Analysis of Experimental Data Study 4- Previous Experience [6]
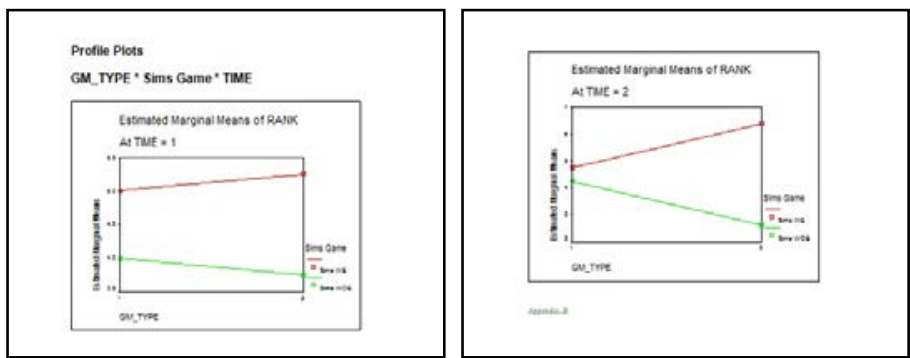

Fig.3: Statistical Analysis of Experimental Data Study 4- Previous Experience [6] Profile Plots
Findings from the experiments have given a six component engagement model comprising of factors acronym as GIFCES (Goals, Immediacy, Feedback, Construct, Experience and Simulation). The experiments have shown that engagement is affected by levels having Construct and Simulation complimenting each other.

There is a need to know more about engagement in other experimental settings using other platforms and application. It is because of this the system was further developed into this presented version NEMD version 2.0. Feedbacks from here will be useful in the development of NEMD version 3.0

\section{An ENGAGEMENT SCALE SCORE}

NEMD version 1.0, a manual version, uses An Engagement Scale Score to measure engagement. Fig. 4 shows how the scale looks like. The scale score were given to users at the beginning of the experiment. In these sheets, a set of eight per sheet for a 40 minute interaction time, users are asked to tick at a scale of 0-10 of the degree of engagement level they were at as they went through interacting with a multimedia system at consistent intervals. The engagement scale is self-declared by users manually through given sheets. A timer is placed at a set of intervals and users were asked to place their feelings every time the bell rings.

Since the users were fully engrossed and immersive in the games or application given to them they often forget to place their indication. In this early experiment a person is employed as a reminder to make sure user ticked when the bell rings.

Even though the presence of the bell and the person does cause some distraction, regular and consistent interruptions at intervals does not distract users' engagement stand. Research in [5] has also proven that users can be engaged, disengaged and reengaged again at any one time.

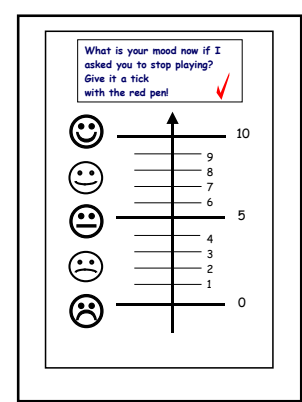

Fig 4: An Engagement Scale Score [1][2][3][4][6][10][11]

The self-declared data is not enough to measure engagement. Facial expressions and exclamations are some indicators of engagement. Therefore in this earlier study to develop the model users' facial expressions were video 
recorded separately. Each facial expression was recorded using cameras at the ceiling, side and the back. The experimental study to test, redesign and retest the model was feasible because it was done in a usability lab in Loughborough University, United Kingdom in from 2002 to 2004 [6]. The building was equipped with cameras at the ceiling, side and the back. Everything is controlled in a room seen and observed by the researcher in another room with a one-way mirror. The interface and the facial expression of the user at the time of interaction were then superimposed to see what goes on at every 5 minutes during interaction. The data then was counter checked with the engagement scale sheets done manually to see which interface engages and disengage users.

As a result, the system is not portable. The screen captures of facial expressions even though occurring concurrently in-real time was separately analyzed by revisiting the superimposed recorded version of the engaging situation. Matters become worst when there is no usability lab in the present institution. Studies to prove the model becomes difficult and unpopular. Situations of setting up experiments to study online and offline activities become very cumbersome. A research team was gathered to develop this system into an all-in-one in-real time invention named as a measuring engagement tool The METM Tool. The system uses an open source operating platform in its' NEMD version 2.0 version NEMD version 3.0 (still in its alpha stage) will be operating on its own platform and will be released soon.

\section{THE INVENTION}

This invention is a consolidation of a copyright and patent pending previous invention, "A Process for Determining Human Engagement Behavior in Multimedia Design System based on Designing Features which Exploit Psychological Needs made known as "The X-Factor in A Multimedia Engagement Behavior". The invention has received a $p$ atent filing number as "A System to Measure Human Engagement Behavior" on $13 \mathrm{M}$ arch 2009. This NEMD version 2.0 is a fully automated system.

\section{NEMD VER 2.0 VERSUS NEMD VER 1.0}

NEMD version 2.0 system has made the whole scientific research process done on young teens 12-17 to develop an Engaging Multimedia Design Model [1,2,3,4] and [6] a much more comprehensive system to measure engagement. Since engagement in online activities have affected people from young teens to adults, all activities of engagement of users aged below, above and beyond 17, going through an engagement behavior whilst interacting with an interface design, could be measured much easily that the previous manually measured system.

\section{THE MEASURING ENGAGEMENT $\left(\mathrm{ME}^{\mathrm{TM}}\right)$ TOOL (NEMD VER 2.0)}

The Measuring Engagement (METM) Tool uses a fully automated visualization method. NEMD version 2.0, is a measuring tool that can be used to measure user engagement level in-real time. The system could give us records of the compilation of screen capture; human face capture; and graphical representation of human engagement behavior as user interact with a multimedia application or an online website. The data are stored in a centralized database. The data collected could be used by developers of multimedia and online application to design, test and redesign a product.

\section{USEFULNESS OF TOOL}

\section{A. Designers and Developers}

This tool is useful to a number of stakeholders. The tool is especially useful to designers and developers of online multimedia applications include e-learning content developers. Designers and developers could use this tool to study the development of multimedia application before, during and after the production process. Such effort enables designers and developers cut down production cost in doing iterative methods. Errors and failures in design especially on disengaging factors could be detected in-real time. The compiled data will help designers and developers produce better quality products. High quality products when mass produced could give positively high monetary returns.

This automated system will enable designers and developers know the overall performance of the designed system as the user interact with them through data collected over a period of time. The record of findings will help designer design or redesign particular spots at a particular time. Designers of websites will be able to design validly engaging products. Therefore the data gathered from this system is especially useful for e-learning content designers to create applications for immersive technologies and futuristic life long learning materials.

\section{B. Researchers}

The development of this automated version can be extended its usefulness even more. The METM Tool of NEMD version 2.0 can cover a wider spectrum of users especially those researching on online activities. Researchers of online activities can determine levels of engagement of the application in-real time with data like screen captures of the user facial expression, screen capture of exact interface location, record of a $\mathrm{p}$ articular point in time of engagement level, and an overall performance of engagement part. All the data are stored in .pdf form.

The .pdf data will be useful to academicians and researchers in learning institutions like schools, colleges and universities studying online activities. The data is useful to those research concerning engaging online activities. Researchers can use data to study on games, effects of social media, harmful addictive online activities of games and websites, cross cultural transfer studies, language discourse studies analysis, etc. Data gathered can help users create 
models and theories in both the sciences and social sciences disciplines.

\section{Research Agents and User Satisfaction Studies}

This tool is also useful for research agents that are commission to measure user satisfaction in websites for commercialization purposes. Its automated system NEMD version 2.0 could accommodate real-time research of studying online activities for research agents doing research analysis for clients of commercial websites; for designers of learning programs e.g. testing smart learning materials for smart learning centers' programs and the like.

The data collected will be kept in the designed database for easy retrievable. From the record research agents will be able to do an analytical study of the website designed by organizations like detecting and suggesting ways to improve customers' design profile. The research agent will be able to tell clients what to do and not do if the application lacks the engagement factor from the data collected over the three forms of data: the facial expressions; the visual interface, and the engagement level. The measure of users' psychological feelings would be made much quicker and easier to complete because each interaction could be measured through visualization as pop-ups on the screen. Whatever is presented could be seen and studied on the spot. In this NEMD version 2.0 automated versions the data can show the rise and fall of engagement pattern of users per interface per facial expressions at a set interval. The overall performance of data will be plotted as graphs and ready to be assigned for data analysis.

\section{Data samples}

The system has been tested in a number of experimental studies and has received good feedback. Students in the Language department have used the system to do many language study research of online activities. E.g. language discourse analysis of bloggers using online systems; identification of rhetoric components in online religious speeches; looking at engagement features in online snooker game; trace metacognitive strategies when engaging in online activities while playing games. A sample given below will give us an overview of the data obtained from the system. Fig.5 represents the logo of the patent filled Measuring Engagement (METM) Tools.

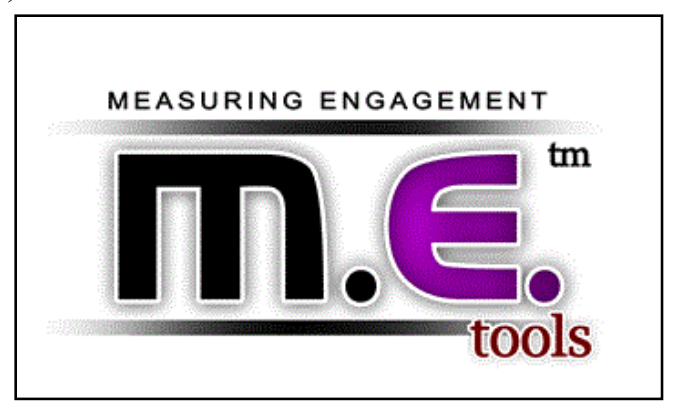

Fig. 5: The Measuring Engagement (METM) Tool Logo
Fig 6 and Fig. 7 shows part of the output got from using the system. Researcher or developer or designer could detect the facial expressions of users and gauge their engagement level as they go through the interaction with the multimedia application of online activities. In Fig. 6 the facial expression at the point of level of engagement for interval 1 is detected.

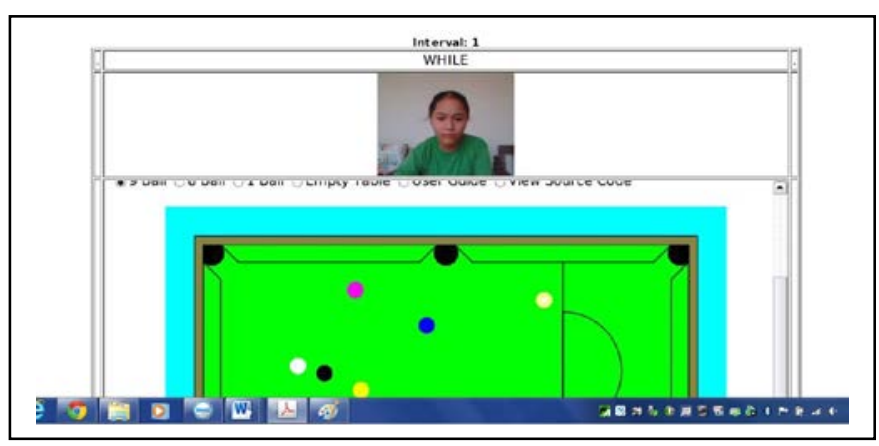

Fig. 6: The Snooker Online Game

Fig. 7 shows a case example of the girl's (in Fig.6) engagement patterns after going through 5 intervals with a space of 5 minute per interval when playing an Online Snooker Game. The data gives an overall performance and engagement patterns of users' engagement behavior. It is with such an output that users of system are able to make full use of the data according to its purpose

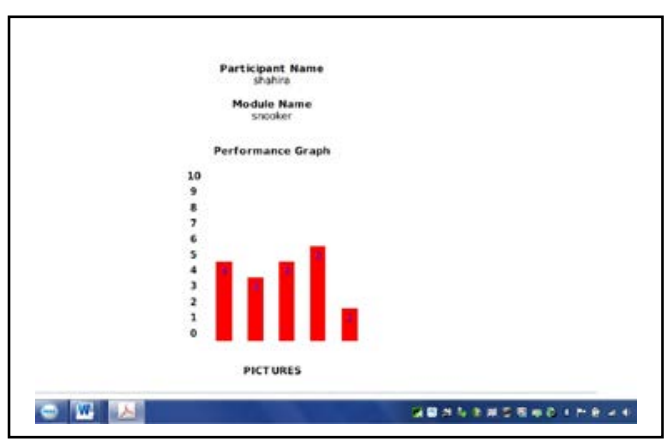

Fig.7: Overall Engagement Patterns Set at every 5-minute Intervals

\section{EXAMPLES OF AN ANALYSIS OF DATA SAMPLE}

Fig. 8 is a s ample of how the given data above in Fig. 7 could help a researcher in analyzing the metacognitive strategies used by the player in playing this Snooker Online Game. Before this let us first define what metacognitive strategies are. By definition metacognition refers to thinking about thinking or cognition about cognition [7] and [8]. Metacognition therefore is defined as "one's knowledge concerning one's own cognitive processes and ...... that influences the execution of cognitive tasks." Through metacognition, a person confronting a cognitive task can select a strategy and then monitor and regulate their progress on a task. The monitoring process allows a p erson to more effectively control his or her cognitive processes, thereby affording more efficient and active learning [9] in [10] 
As far as gaming activities are concern, metacognitive strategies involves strategic planning, monitoring, and regulating action. The steps taken are more specifically of planning that involves goal settings, generating questions, analyzing how to achieve the target goal, and selecting and organizing information for one's decision. Through regulating action, a child modifies the actions or decisions in order to achieve the goal. [10]

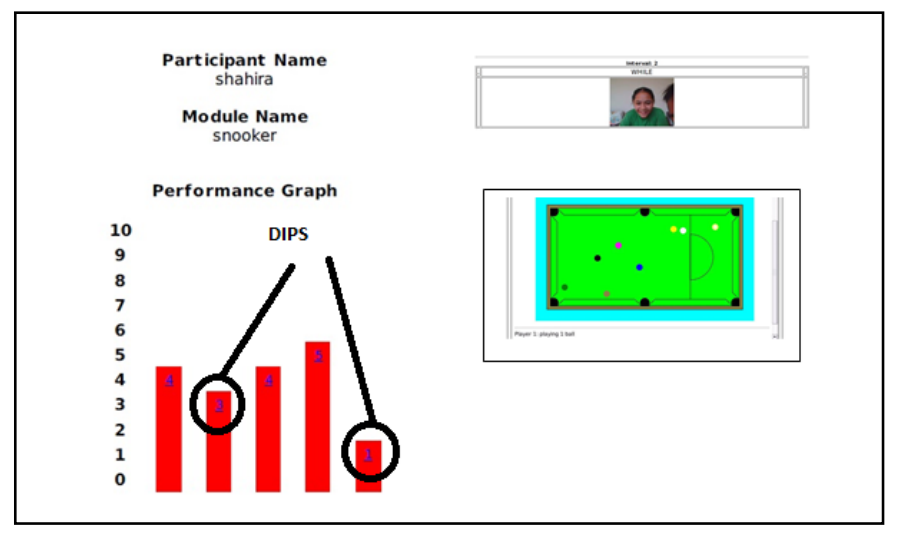

Fig.8: 'Dips' as a form of 'disengagement'

When doing a metacognitive analysis of this case, a researcher will look closely at these engagement patterns and try to trace reasons why it occurs. In Fig. 8, the fall in engagement is known as 'dips'. Dips are evidence of some form of 'disengagement'. The data will enable a r esearcher use an analytical and critical judgment as to 'Why it happens' and 'when it happens'. Implementing the metacognitive strategies of planning, monitoring and evaluating into the patterns of engagement behavior collected will help the researcher justify the cause of this rise and fall phenomenon. Refer to [10] for a more comprehensive study of metacognitive strategies studies of gaming activity.

The emerging pattern of engagement could be classified into seven categories:

1) Low levels of engagement

2) The starting level range

3) Dips

4) Gradual increase and gradual decrease

5) Plateaus

6) Maximum

7) The ending level range

The description of these categories is based on three sources:
a. Comparing data
b. Scores of Engagement that fit the discussed category
c. Individual Cases Examples.

The above category was used in [10]. However for this case only 'dips' at the starting and ending point will be discussed in analyzing the likely metacognitive thinking strategies that occurs during interaction. The first 'dip' is after the first starting interval and the second 'dip' after the highest engagement level.

\section{METACOGNITIVE STRATEGIES ANALYSIS}

Here is an example of how a metacognitive strategies data analysis could be done of the above case study of the girl in Fig.8. The girl started by marking a 5/10 score when playing the game for the first time. After 10 minutes into the game the score went down to 3/10. (In metacognitive strategies analysis this would mean the child starts to evaluate the outcome of the action after a first encounter excitement. The unknown factor or fear of the unknown has caused some form of disengagement).

Observing other patterns it could be seen that there was a gradual increase in engagement patterns from the second to the third and the fourth interval after 30 minutes of playing the game. (In metacognitive strategies this would mean that the girl has now feels 'in control' of the game. Thus, she could plan, monitor and evaluate every steps of the game easily using strategies she has learned and used before, therefore at this stage, her engagement was at its maximum level.) Maximum engagement therefore is at the time when the girl has reached her targeted goals.

However, as in most games, designers will change a challenge and the girl is faced with a new challenge and obstacles. This usually happens every time a player encounters a new challenge immediately after achieving a win. (In metacognitive strategies analysis this would mean that the child starts to reevaluate the outcome of an action to overcome this new challenge.).

Identifying the likely metacognitive strategies could be one form of iterative method a designer could use to design engaging educational and entertaining multimedia application and websites. Knowing metacognitive strategies' characteristics and identifying it with an engaging interactive game-play experience could give us insights into features that could be included when designing engaging materials. This system could assists designers in doing just that. Here a researcher who is studying on metacognitive strategies could use this system to detect what movements the girl made when playing the game.

\section{OTHER SUGGestions For ANALYSIS}

From the data a designer or developer could use the data to detect usability issues on design products like games and websites, in this case, usability of the snooker game designed for online gaming. The system could be customized by the user of the system according to their need. Users of system could set the timing of intervals at any given time they like. They can customize it according to their own research demands. Thus in this way researcher, developer or designer could get to see all the interfaces set according to intervals in order to do a 
comprehensive study on the chosen subject matter for online researchers. A research agent can use this data to detect most frequent visit products on selected websites. Webmaster, playing a role as moderator, could revamp or add certain things to the website created by them. Designers and developers of multimedia application whether online or offline could detect 'faults' or 'disengagement' in design to redesign a system for use in iterative methods.

\section{CONCLUSION}

From the above it could be concluded that The Measuring Engagement (METM) Tool is a tool that can measure engagement and disengagement that can describe human engagement behavior whilst interacting with any form of online multimedia environment. The Measuring Engagement (METM) Tool automated system is a much feasible system from the one done manually. The system has proven to be a useful tool to enable us knows more about engagement and the phenomenon surrounding it. Besides knowing more about engagement and disengagement, the system could also help designers detect faults and pitfalls in design of online kiosks like websites, online gaming and educational application especially that of the ones design for e-learning activities. The system could also help researchers know more about engagement that may lead to excessive, immersive and addictive use of innovative technologies to prepare our future generation to be aware of the consequences and potentials of our future Net-gens living in this Digital World. Feedback and comments are most welcome to make NEMD version 3.0 a better tool to measure engagement.

\section{ACKNOWLEGMENTS}

A great appreciation to Universiti Putra Malaysia (UPM) for giving us the opportunity and support to continually pursue research on games under the Games and Gamification for Social Engineering Research Group, and from funding of the RUGS (Research University Grant Scheme), UPM. Special thanks is also conveyed to the PRGS (Prototype Research Grant Scheme) offered by the Ministry of Education under the Higher Education Division of the Government of Malaysia in continually supporting the development of this system to measure engagement and addictiveness into a much better system for the coming NEMD ver 3.0 version which will be released in the near future.

\section{REFERENCES}

[1] NS Said, "An engaging multimedia design model". Proceedings of Interaction Design and Children 2004 Building a Community http://www.idc2004.org June 1-3 2004 Maryland, USA. ACM digital library, the Association of Computer Machineries (ACM) Press: New York. Volume 15. Issue No. 2 (September). p.169 - 172. ISBN: 1-58113 - 791 - 5. (2004).

[2] NS Said, "Why children and teenagers are addicted to computer games?" N EMD Model (Norma TM Engagement Multimedia Design Model)".Synthesis - R \& D Digest of Universiti Putra Malaysia. Issues 17-19 (combined Issues) December 2007.p.7. ISSN: 0127 - 9394. (2007).

[3] NS Said, "An engagement model - A modeling theory that explains engagement whilst interacting with a multimedia design application." Digital Learning Online DL Asia 07/ABS /162. www.digitallearning.in . (2007)

[4] NS Said, "X-factor in a multimedia engagement behaviour- The NEMD Model (Norma ${ }^{\mathrm{TM}}$ Engagement Multimedia Design Model)". Proceeding of the 4th Annual Conference on Computer Games, Multimedia and Allied Technology (CGAT 2011) Eds. Prakash, Edmond. And Murugesan, S. (25-26 April 2011) Hotel Equatorial Penang, Malaysia ISBN: 978-981-08-8644-8.(2011).

[5] Heather L. O'Brien, Elaine G. Toms "What is user engagement? A conceptual framework for defining user engagement with technology" Journal of the American Society for Information Science and Technology. Volume 59, Issue 6, pages 938-955, April (2008)

[6] NS Said, “An Experimental Study to Develop An Engaging Multimedia Design Model” PhD Thesis Unpublished (2005)

[7] Wellman, H.. "The origins of metacognition." In Forrest-Pressley, D.L. ; MacKinnon, G.E. \& Waller, T.G., (Eds.), Metacognition, Cognition, and Human Performance. Volume 1: Theoritical Perspectives (pp. 1 - 32). New York: Academic Press, Inc. (1985)

[8] Flavell, J.H. "Metacognitive aspects of problem solving." In Resnick, L.B., (Eds.), The Nature of Intelligence (pp. 231-235). Hillsdale, New Jersey: Lawrence Erlbaum Associates, Publishers. (1976).

[9] Bond, C., Bond, L. and Peach, W. "Metacognition: Developing independence in learning". Clearing House, Vol. 66 No. 1, pp. 56-9. (1992).

[10] NS Said, Saemah Rahman, and Siti Fatimah M. Yassin "Revisiting an engaging experience to identify metacognitive strategies towards developing a multimedia design model" International Journal of Education and Information Technologies Volume 3. Issue 2. p.115-125 ISSN: 2074 - 1316 (2009).

[11] NS Said, Saemah Rahman, Siti Fatimah Yassin "A case study on Metacognitive Strategies in an Engaging Multimedia Experience". Proceedings of the $7^{\text {th }}$ WSEAS International conference on education and educational technology (EDU'8) 224-230. Venice, Italy. 21-23 November 2008. WSEAS Press. www.wseas.org ISSN: $1790-5109$. ISBN: $978-960-474-029-1(2008)$.

\section{Creative Commons Attribution License 4.0 (Attribution 4.0 International, CC BY 4.0)}

This article is published under the terms of the Creative Commons Attribution License 4.0 https://creativecommons.org/licenses/by/4.0/deed.en US 